\title{
Research on Business Environment Risk Governance Based on Occupational Claims: 1784 Cases of Food Safety Disputes
}

\author{
Jiangjie Sun $\left(\mathbb{D},{ }^{1,2}\right.$ Yufei Gao, ${ }^{2}$ Xueli Jiang, ${ }^{2}$ Yan $\mathrm{Li}^{3}{ }^{3}$ Mengyao Yang, ${ }^{3}$ Ziyan Zhao, ${ }^{3}$ \\ Hangzhou Yang, ${ }^{3}$ and Jinliang You (iD ${ }^{4}$ \\ ${ }^{1}$ Center for Data Science in Health, Anhui Medical University, Hefei 230032, China \\ ${ }^{2}$ Health Management College, Anhui Medical University, Hefei 230032, China \\ ${ }^{3}$ Clinical Medical College, Anhui Medical University, Hefei 230032, China \\ ${ }^{4}$ Law College, Anhui Medical University, Hefei 230032, China \\ Correspondence should be addressed to Jiangjie Sun; sunjiangjie@ahmu.edu.cn and Jinliang You; 841450201@qq.com
}

Received 12 May 2021; Accepted 24 July 2021; Published 17 August 2021

Academic Editor: Abdelalim Elsadany

Copyright (C) 2021 Jiangjie Sun et al. This is an open access article distributed under the Creative Commons Attribution License, which permits unrestricted use, distribution, and reproduction in any medium, provided the original work is properly cited.

There are disputes on the legal acceptance of occupational claims and the risk of occupational claim spoiling business environment is skyrocketing. How to manage the risk of occupational claims in the business environment is the subject of urgent research, especially COVID-19 is ravaging the world and the risk of economic crisis is increasing dramatically. In this study, we collected 1784 cases of food occupational claims from the Chinese legal documents website. Using Excel, Review Manager 5.0 and SPSS 19.0, the number of cases prosecuted as "consumers" were obtained by means of textual analysis, and the development process was directly influenced by occupational claims, with 2017 as a great value point (watershed); the rate of losing occupational claim cases has been climbing since 2018; and the risk of losing occupational claims is higher than that of true meaningful consumer advocacy cases $(Z=6.99, p<0.001)$, and in 2019, the risk of losing a case was 33.34 times higher than that of an ordinary consumer. The proportion of occupational claims in the total number of food safety disputes is positively correlated with official protective behavior; the failure rate of occupational claims is positively correlated with official regulatory behavior. The results show that occupational claims are being reexamined by society; the continued rise in the number of unsuccessful occupational claims cases indicates a lack of regulatory guidance for their profit-making behavior, the existence of malicious reporting complaints against business behavior, damage to the business environment, and a certain lack of legality. Therefore, it is proposed that laws and regulations should be in line with international standards, highlight the legal thinking and the concept of the rule of law, return to the original legislative intent, and build a five-inone mechanism of "consumers, operators, media, government, and justice" to coordinate the management of occupational claims, crack down on occupational claims, and contribute to the creation of a good business environment.

\section{Introduction}

The 19th National Congress of the Communist Party of China reported the scientific improvement of the food safety governance system and the construction of a new pattern of social governance with universal participation and shared governance of food safety [1]. Xi Jinping emphasized the importance of preventing and resolving governance risks in food safety and other areas, fostering new opportunities amid challenges and making new advances amid changes. In the author's view, the attributes of occupational claims in the process of food safety governance are evolving, developing through three stages: "indeterminate attributes in the budding stage, positive attributes in the middle stage, and negative attributes in the later stage." The risk management of occupational claims requires the participation of the society, government, and judiciary in multiple dimensions.

Occupational claim is the act of claiming compensation from the operator by purchasing defective products (such as label markings, additives, and shelf life) from a self-cognitive perspective with the purpose of profit, based on the punitive damages provisions in the Law of the PRC on the Protection 
of the Rights and Interests of Consumers, the Food Safety Law, and other laws and regulations [2]. Punitive damages were first introduced in the UK in 1763 and developed in the US in 1784 as one of the most important systems in the civil and criminal fields $[3,4]$. In 1994, it was introduced into China, forming the punitive provision of Article 49, "return one to compensate one," of the Law on the Protection of the Rights and Interests of Consumers, and the occupational claims represented by "Case of Wang Hai" were inaugurated in China. Combined with the basic national conditions in the 1990s, the low level of science and technology, the backward economic development, and the numerous product quality defects [5], occupational claims behavior objectively forced the improvement of commodity quality and played a positive role in the innovation of consumer perceptions and operators' concepts. On December 9, 2013, the Supreme People's Court issued regulations on the application of the law to the trial of food and drug disputes, making it clear for the first time that "knowingly buying a fake" is protected by law. The revision of the Law on the Protection of the Rights and Interests of Consumers, which explicitly provides for " 3 times compensation," and the Food Safety Law, which provides for "10 times compensation," had further boosted the wave of occupational claims [6]. According to the disclosure of Shanghai Municipal Administration of Industry and Commerce, the number of occupational claims cases increased by an average of 364\% per year between 2013 and 2016. The huge increase in the number of occupational claims cases due to the interestdriven punitive damages led to a sudden increase in the number of occupational claims complaints from the grassroots administration and occupational claims disputes in the courts, resulting in a serious waste of administrative resources and an imbalance between administrative costs and benefits.

With low threshold and utilitarian nature, occupational claims have become gang-oriented, large-scale, and professional in operation and even distorted the organizational form of building personnel with clear division of labor and process-oriented claims [7]. The negative impact of the profit-making nature of their occupational claim behavior far outweighs the positive impact. In March 2016, the Chongqing Senior People Court took the lead in issuing the "Answers to Several Questions on the Trial of Consumer Rights and Interests Protection Disputes," which states that a person who purchases goods or services knowing that they have quality problems is a consumer. However, the court will not support a request for punitive damages from a person who purchases goods or services knowing that they have quality problems, because it is against the principle of integrity. On December 6, 2016, the Jiangsu Senior People Court proposed the provisions of the Discussion Minutes (2016) No. 10 on Several Issues regarding the Trial of Consumer Rights and Interests Protection Disputes: for the field of food consumption, the elements of punitive damages are that the seller operates food that he knows does not meet food safety standards, except for natural persons, legal persons, or other organizations that purchase it for the purpose of profit.
To this point, the jurisprudential disputes between occupational claims and distributors have continued [8]. We have been organized based on the line of jurisprudential development of food safety disputes, as shown in Table 1 .

Occupational claims have always been wandering in the edge of violation of law, and it is controversial whether the behavior of occupational claimants upholds social justice or undermines the business environment. The regulation of occupational claimants' behavior is directly related to the risk management of the healthy development of the business environment.

\section{Subjects and Methods}

2.1. Subjects. We comprehensively searched the database from 2011 to 2019 using the Chinese legal documents website, a public database of court closing case. Following keyword terms were searched in the database: referee year ('2011', '2012', '2013', '2014', '2015', '2016', '2017', '2018', '2019'), civil case, sales, and purchase contract disputes and type of instrument ("judgment" and "ruling"). The criteria to qualify are as follows: (a) topics are food defects; (b) the plaintiff is an individual. Exclusions are as follows: (a) case filed in 2010 and closed in 2011; (b) case filed in 2019 and closed in 2020; (c) topics are drug defects; (d) the defendant is a pharmaceutical company.

2.2. Data Extraction. The following data were extracted from the included studies: year of case occurrence, classification of case attributes (the number of cases made by the same subject is 2 or more which was defined as occupational claims, occupational claims were recorded as 1 , and nonoccupational claims were recorded as 0$)$, result of the case (1 for a successful case' -1 for an unsuccessful case), and behavior of occupational claims official regulation (in this article, official refers to the justice, government, and media; issuance of $n$ country-level documents noted as $2 n \%$; protective documents are counted as positive values, and regulatory documents are counted as negative values; the relevant documents that are not available are recorded as 0 ; the provincial and ministerial level documents are assigned $50 \%$ of the national level documents; the media monitoring is assigned $50 \%$ of the national level documents). Two researchers independently evaluated the legal instruments and reached consensus on all data. Data were matched using a double-entry method to ensure error-free data entry.

2.3. Methods. Using Excel software to fit data to the distribution of the sample data, explore the trend of the number of occupational claims and analyze the trial results of food safety disputes. Review Manager 5.0 software was used to analyze the risk of losing an occupational claim. SPSS 19.0 software [9-12] was employed to explore the correlation between official behavior and year, the share of occupational claims in the total number of food safety disputes and official protective behavior, and the failure rate of occupational claims and official regulatory behavior. Excel software was used to explore the moderating effect of official regulation of 
TABLE 1: Food safety dispute jurisprudence development line.

\begin{tabular}{|c|c|c|c|}
\hline Time node & Judicial behavior & Official behavior & Media behavior \\
\hline January 1, 1994 & Refund 1 to compensate 1 & & \\
\hline February 28, 2009 & 10 times compensation & & \\
\hline March 15, 2014 & Refund 1 to compensate 3 & & \\
\hline March 25, 2016 & CSPC & & \\
\hline December 6, 2016 & SIRTCRIPD & & \\
\hline May 19, 2017 & REOCOB & & \\
\hline November 7, 2018 & & OCOCCAP & \\
\hline December 29, 2018 & 10 times compensation* & & \\
\hline March 13, 2019 & & & СOCPBE \\
\hline March 18, 2019 & & LMMVBPEFF & \\
\hline May 9, 2019 & & CDMRIPMB & \\
\hline August 8, 2019 & & CDEFAC & \\
\hline November 26, 2019 & & RPOC & \\
\hline December 1, 2019 & & IFSMS & \\
\hline December 6, 2019 & & & Beijing TV \\
\hline December 7, 2019 & & & Metro Newspaper \\
\hline April 20, 2020 & & FPMRBSME & \\
\hline December 11, 2020 & & & a Central Television \\
\hline
\end{tabular}

Note. Refund 1 to compensate 1: the fourth session of the Standing Committee of the 8th National People's Congress adopted the Law of the People's Republic of China on the Protection of Consumer Rights and Interests, proposing "refund 1 to compensate 1"; 10 times compensation: the seventh session of the Standing Committee of the Eleventh National People's Congress voted on the Food Safety Law of the People's Republic of China, proposing "10 times compensation"; refund 1 to compensate 3: the fifth session of the Standing Committee of the 12th National People's Congress passed the Law on the Protection of Consumer Rights and Interests, proposing "refund 1 to compensate 3"; CSPC: Chongqing Senior People Court's "Answers to Several Questions on the Trial of Consumer Rights and Interests Protection Disputes" provides for punitive damages for consumers: "if a person who purchases goods or services knowing that there are quality problems requests punitive damages, the people's court shall not support it because it is against the principle of integrity"; SIRTCRIPD: restrictions on obtaining punitive damages in the Jiangsu Senior People Court's Discussion Minutes (2016) No. 10 on Several Issues regarding the Trial of Consumer Rights and Interests Protection Disputes; REOCOB: suggestions of the Supreme People's Court on guiding and regulating occupational counterfeiting, proposing to "reexamine occupational claims and other behaviors"; OCOCCAP: Shanghai Market Supervision Bureau, Shanghai Municipal Office of Legal Affairs and other seven departments jointly issued the "Guidance on Effective Response to Occupational Claims and Occupational Reporting Behavior to Maintain the Business Environment" (Shanghai Municipal Administration of Industry and Commerce (2018) No. 910), proposing to differentiate "occupational claims and ordinary consumers," and to classify and apply policies; 10 times compensation*: the seventh session of the Standing Committee of the Eleventh National People's Congress voted on the Food Safety Law of the People's Republic of China, proposing 10 times compensation for violations under informed conditions; COCPBE: Hong Mingii, a member of the National Committee of the Chinese People's Political Consultative Conference (CPPCC), proposed a motion on "combating occupational claims and optimizing the business environment"; LMMVBPEFF: Shanghai introduced the "list of minor market violations of business practices exempt from fines"; CDMRIPMB: the State Council issued "opinions on deepening reforms to strengthen food safety," proposing to crack down on malicious reporting illegal profit-making behavior; CDEFAC: the General Office of the State Council issued the "Guidance on Promoting the Standardized and Healthy Development of the Platform Economy," proposing to effectively protect the legitimate rights and interests of participants in the platform economy and to crack down on extortion in the name of "fighting against counterfeit"; RPOC: the State Administration for Market Regulation issued "Interim Measures for Handling Market Supervision and Administration Complaints and Reports" to put forward restrictive provisions for occupational claims, officially implemented since January 1, 2020; IFSMS: the State Council issued "Regulations on the Implementation of the Food Safety Law of the People's Republic of China" to improve the food safety management system; Beijing TV: Beijing TV promotes the spirit of "the General Office of the CPC Central Committee and the State Council demands to crack down on occupational claimants"; Metro Newspaper: Metro Newspaper wrote "stopping occupational claims"; FPMRBSME: Guiding Opinions of the Supreme People's Court on "Several Issues concerning the Proper Trial of Civil Cases Involving the Novel Coronavirus Pneumonia Epidemic According to Law (I)," which proposed "flexible preservation measures to reduce the burden of the small and microenterprises"; China Central Television News: China Central Television News propagated "market supervision and management complaints and reports processing interim measures" of the restrictive provisions of occupational claims, clearly cracking down on occupational claimants.

occupational claims on the number of occupational claims and that of unsuccessful occupational claims. $p<0.05$ was considered to be statistically significant.

\section{Results}

3.1. Current Development of Food Safety Dispute. The search years ranged from January 1, 2011, to December 31, 2019, with a cumulative total of 1,784 cases regarding food disputes during the 9-year period, with an upward trend in the number of cases, reaching a peak during 2017-2018 and then declining. The development trend is shown in Figure 1.

Before 2017, the number of cases won by consumers as plaintiffs was on an upward trend; since 2017, it had been on a downward trend, and the winning rate in 2018-2019 was significantly lower than that in 2017-2018. The number of unsuccessful plaintiffs in case trials was on a steady upward trend.

\subsection{Trends of Occupational Claims in Food Safety Disputes.} The search years ranged from January 1, 2009, to December 31,2019 , and the number of lawsuits initiated by occupational claimants was as high as 1,530, accounting for $85.76 \%$ of the food safety lawsuits.

Combining Figures 1 and 2, it is easy to see that the trend in the number of occupational claims is directly related to the trend of food safety disputes. Figure 2 shows that the total number of occupational claims has generally shown a fluctuating increase, peaking in 2018. The number of successful 


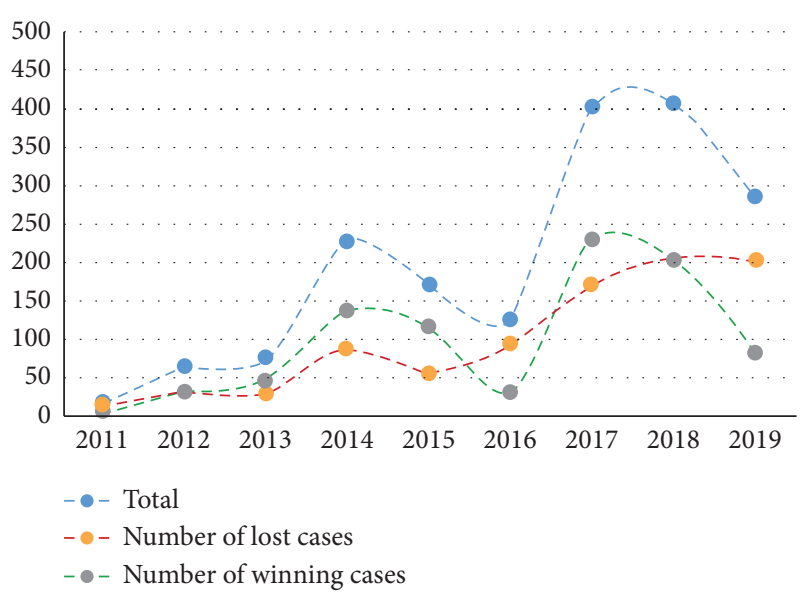

Figure 1: The trial trends of food safety disputes.

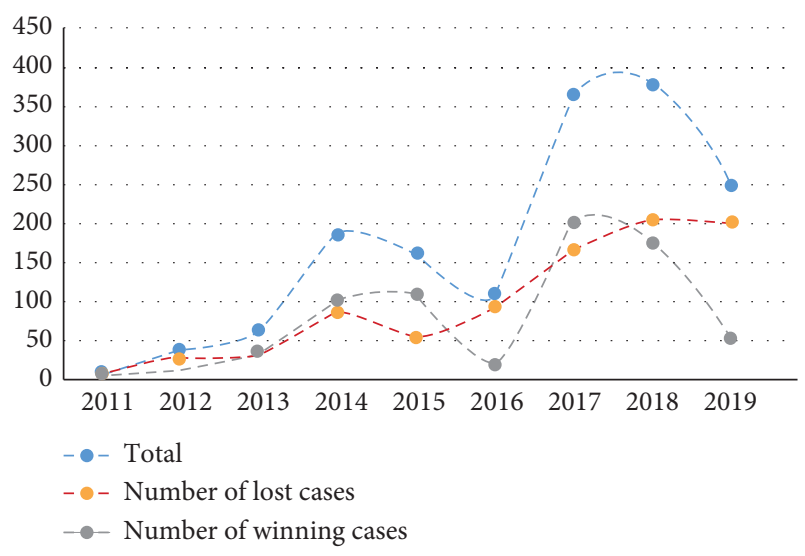

Figure 2: The trial trends of occupational claims disputes.

occupational claims cases continued to be high until 2015, before hitting a low point for the first time in 2016. In 2017, occupational claimants once again worked rampantly and the number of successful cases climbed sharply; since the start of 2018, the number of successful occupational claims has plummeted. The number of lost occupational claims cases had been climbing since 2011, and the current data estimate that the number of that will reach its peak in 2020 .

3.3. Trends in the Failure Rate of Occupational Claims in Food Safety Disputes. During the period of 2011-2019, there were 2 maximum values and 2 minimal values in the trial loss rate of occupational claims in food safety disputes, with the maximum values in 2012 and 2016 and the minimal values in 2015 and 2017, respectively, and the occupational claims trial loss rate had continued to climb since 2018. See Figure 3 for details.

3.4. Analysis of the Risk of Losing Occupational Claims in Food Safety Disputes. Using Review Manager 5.0 software [13], we conducted a study on the risk of losing a trial for the full set of food safety disputes from 2011 to 2019 and found that there was a statistically significant difference in the rate of losing an occupational claim and a true consumer rights

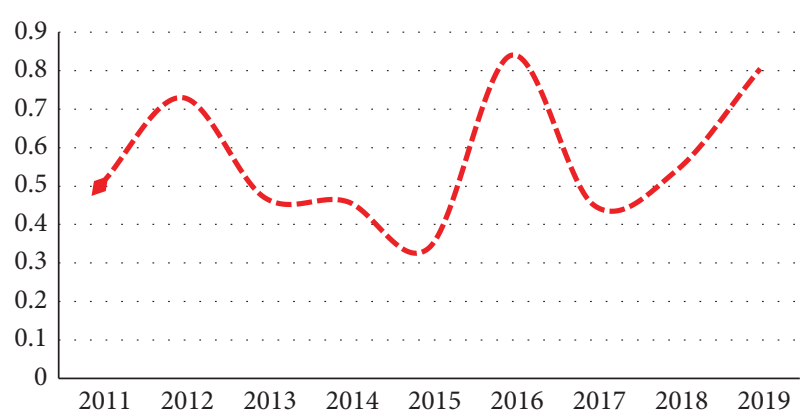

FIgURE 3: Rate of lost cases in occupational claims disputes.

defeat rates $(Z=6.99, p<0.001)$. In 2019, the risk of losing an occupational claim is 33.34 times that of losing a consumer rights claim in the true sense (see Figure 4).

\subsection{The Moderating Effect of Official Regulatory Behavior on} Occupational Claims Trials. Analysis by SPSS 19.0 software showed a negative correlation between official behavior and year $(r=-0.63, p<0.05)$; the share of occupational claims in the total number of food safety disputes was positively correlated with official protection behavior $(r=-0.90$, $p<0.05$ ), and the rate of losing occupational claims was positively correlated with official regulatory behavior $(r=0.53)$.

On this basis, we used Excel software to explore the moderating effects of official behaviors (protective and regulatory behavior) on rate of lost cases in occupational claims and percentage of occupational claims in total, respectively. The specific results are shown in the following series of graphs.

The trend line in Figure 5 shows that official protective policies are relatively stable and the introduction of regulatory policies for occupational claims is relatively delayed. Throughout the consumer rights protection process, there has been a fluctuating increase in the rate of losing occupational claims. Official protective policies increase the winning rate of occupational claims. The more obvious the official regulatory behavior, the higher the likelihood of losing an occupational claim. There is a time lag in the effectiveness of official behavior.

The trend line in Figure 6 shows that throughout the consumer rights protection process, continued growth in occupational claims as a share of total food safety dispute cases was stably drove by official protective policies.

The trend line in Figure 7 shows that throughout the consumer rights protection process, official regulatory policies had steadily constrained the share of occupational claims in the total number of food safety disputes.

\section{Discussion}

The results of the study show that food safety issues are taken seriously by society and that the number of food safety disputes is generally on an increasing trend. One of the possible reasons is that, based on China's national conditions, the country's technological level was not high at the 


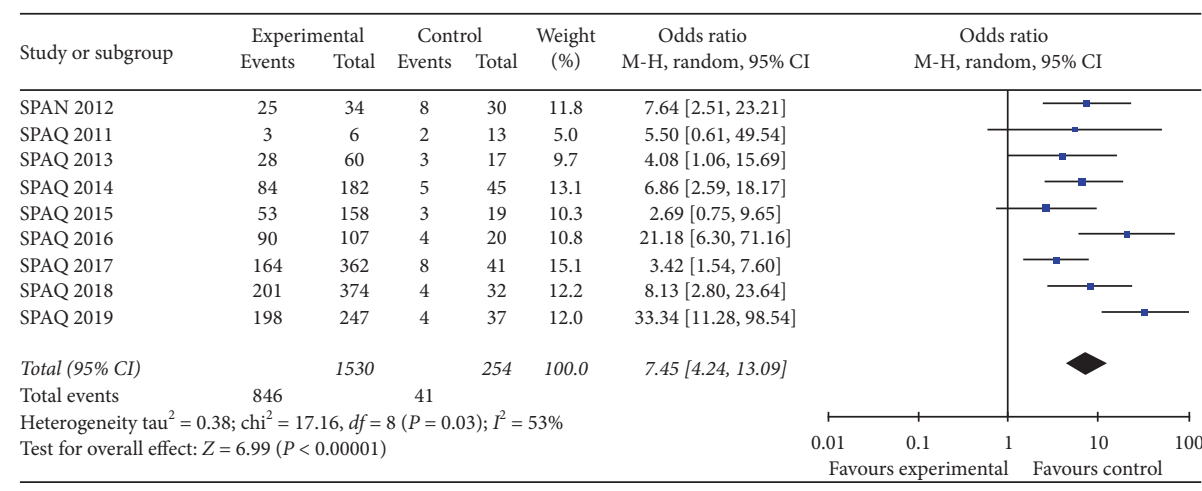

FIgURE 4: Risk of lost cases in occupational claims and actual consumers.

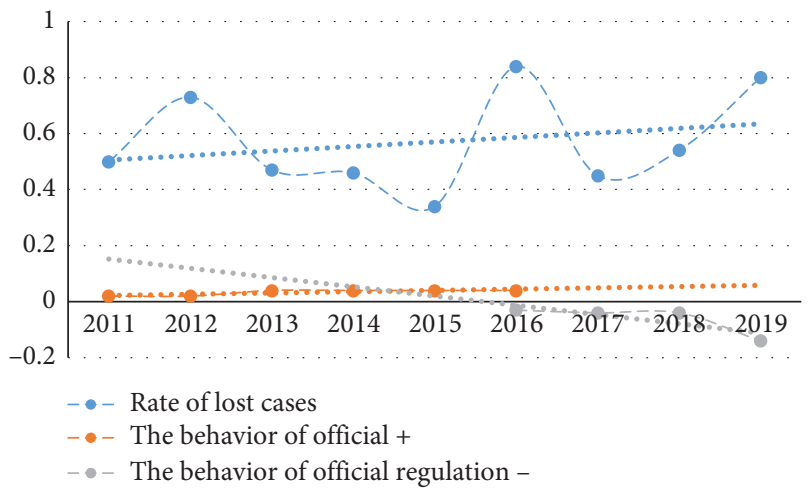

FIGURE 5: The moderating effect of official regulatory behavior on rate of lost cases in occupational claims.

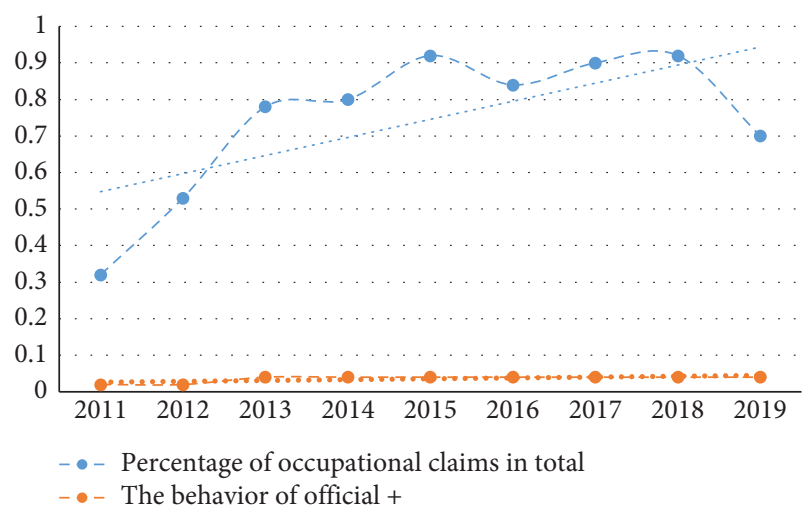

FIGURE 6: The moderating effect of official protective behavior on percentage of occupational claims in total.

end of the 20th century and the quality of food production needed to be improved. The second reason may be due to the conflict between the public's expectations of food safety production and the lack of actual production capacity in the society, combined with the official introduction of Protection of the Rights and Interests of Consumers and the publicity effect of the media, which has raised public awareness of safety $[14,15]$. The third reason for this may be that the amendment and upgrading of the Consumer Protection Law, which introduced the provision of "refund 1 to compensate 1 " to "refund 1 to compensate 3 ," have to a

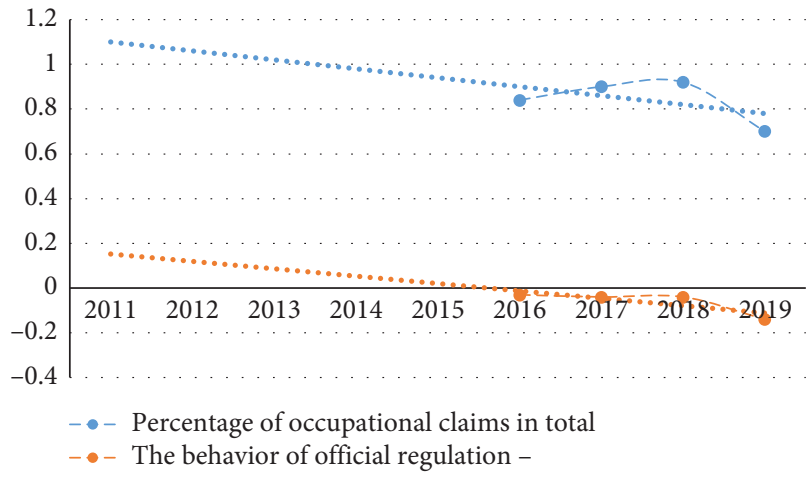

Figure 7: The moderating effect of official regulatory behavior on percentage of occupational claims in total.

certain extent given rise to the phenomenon of occupational food safety claims, such as "Case of Wang Hai" [16]. The "10 times compensation" provision in the Food Safety Law, which was legislated in 2009, amended in 2013, and implemented in 2015, has largely become a "booster" for occupational claims. This may be the fourth possible reason, because a large number of small businesses or outlets, with little money involved, responded relentlessly and gave up responding to lawsuits, resulting in occupational claimants who can obtain 10 times the compensation without any effort and were happy to do so, pushing up the total number of food safety disputes. Other possible causes cannot be excluded.

The results of this study show that "occupational claims" account for $85.76 \%$ of food safety disputes, directly affecting the rational allocation of administrative and judicial resources. The number of unsuccessful occupational claims continues to climb. The possible reasons for this are that occupational claimants have exploited legal loopholes and abused the right to file complaints and reports, administrative review, and litigation. According to scientific statistics, occupational claims consume 4-5 times more administrative and judicial resources than normal consumer disputes. One of the reasons for the continued rise in the number of unsuccessful occupational claims is the upward trend in the total number of food safety disputes. The second reason may be related to occupational claimants "making profits in the name of fighting against counterfeiting." 


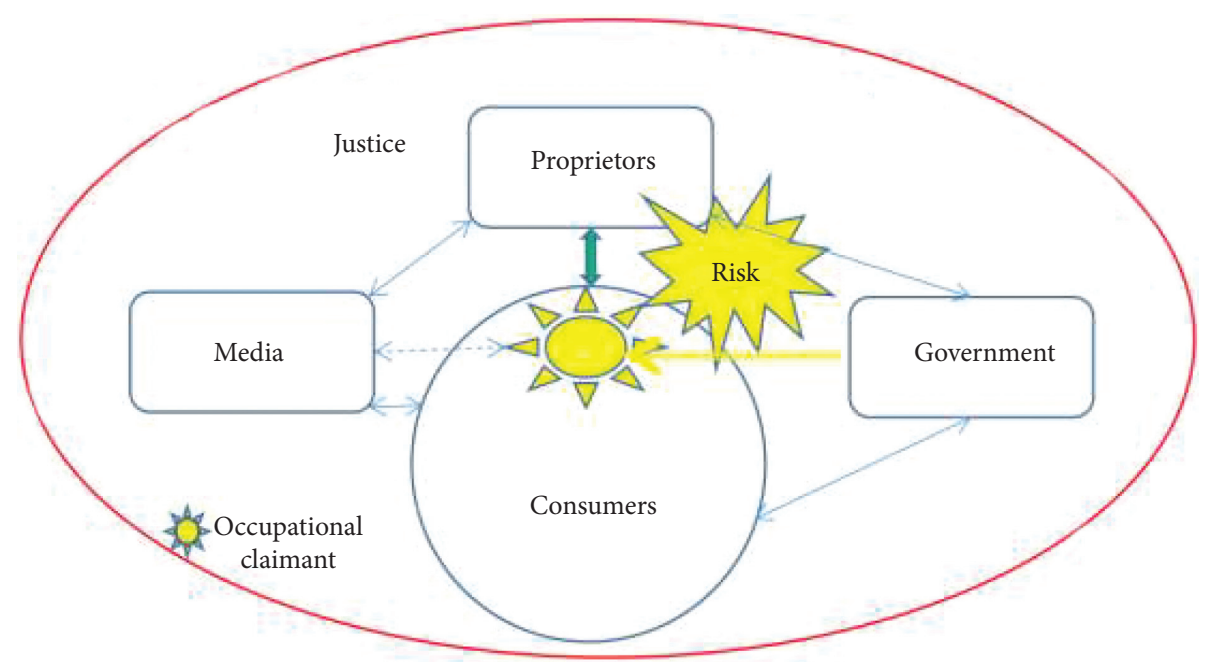

FIGURE 8: Five-in-one mechanism to coordinate the management of occupational claims.

Occupational claims behavior violates the principle of integrity, damages the market business environment, and is harmful to social stability and economic development.

The results of this study show that the loss rate of occupational claims first increased, then decreased, then increased, then decreased, and finally showed an increasing trend during the period 2011-2019, which is consistent with the law of social administrative intervention. Since the implementation of the Protection of the Rights and Interests of Consumers in 1994, the "refund 1 to compensate 1" rule has created "occupational counterfeiters" represented by "Wang Hai," occupational counterfeiters are welcomed by the public based on forcing product quality improvement. The role of "occupational counterfeiters" has changed to that of "occupational claimants" due to financial interests. Before 2011, there was an upward trend in the rate of losing occupational claims, probably due to inexperience with occupational claims. The newly revised Consumer Protection Law of 2011 with 3 times compensation and the Food Safety Law of 2009 with 10 times compensation accelerated the wave of occupational claims. Having the experience of losing occupational claims in the earlier period made it understandable that the loss rate had continued to decline from 2012 to 2015. The phenomenon of occupational claims is further exacerbated by the lure of financial gain and even the emergence of a large number of jobless people, specializing in occupational claims. The occupational claims represented by "Xing Zhihong" amounted to as much as 1 million, shocking the industry and causing concern of the national regulatory authorities. The public and official have re-examined the behaviors of the occupational claims and reconsidered the original legislative intent of the Protection of the Rights and Interests of Consumers and the Food Safety Law, and the outcome of the public and official reflections will negatively affect the outcome of the occupational claims trial. As a result, the rate of losing occupational claims reached a high point again in 2016. People can always find a way to cope with the government policies. Occupational claims have become gangoriented, large-scale, and professional in operation and even distorted the organizational form of building personnel with clear division of labor and process-oriented claims, which brought the loss rate of occupational claims down again to $45 \%$ in 2017 . This result may also be related to the "Regulations on the Implementation of the Consumer Rights Protection Law (Request for Comments)" issued by the State Administration for Industry and Commerce on August 5, 2016, which proposed to stipulate that "acts for profit are no longer protected by the Consumer Law." Nonetheless, at this time, there is regional variation in the outcome of domestic occupational claims trials, due in large part to the provision for punitive damages for consumers in March 25, 2016, Chongqing Senior People Court's “Answers to Several Questions on the Trial of Consumer Rights and Interests Protection Disputes": "if a person who purchases goods or services knowing that there are quality problems requests punitive damages, the people's court shall not support it because it is against the principle of integrity" and restrictions on obtaining punitive damages in the Jiangsu Senior People Court's Discussion Minutes (2016) No. 10 on Several Issues regarding the Trial of Consumer Rights and Interests Protection Disputes. Since the beginning of 2018, the rate of losing occupational claims had skyrocketed, and one of the reasons may be related to the fact that on May 19, 2017, the Supreme People's Court proposed to "reexamine occupational claims and other behaviors." The second reason may be related to the official regulatory behavior and social concern about the heat of occupational claimants, for example, the State Council issued a document on cracking down on occupational claimants, as well as the publicity coverage of Beijing TV, CCTV news, and other major media.

The results of this study point out that the risk of losing an occupational claim case is higher than that of normal consumption. The main reason for this is that the motivation of occupational claims is contrary to the original legislative intent of the Consumer Protection Law and the Food Safety Law, "the prevailing norm of international legislation is to use "fraud" as a premise for punitive damages" [17, 18]. The risk of losing an occupational claim in 2019 is 33.34 times 
higher than a normal consumer dispute, as evidenced by the fact that occupational claim losses are directly related to official regulatory behavior. The secondary reason may be that occupational claims are not in line with public sentiment and are contrary to socio-economic development. Further, it may be due to occupational claims overly pursuing financial interests and misclassifying the focus of the dispute. Most of the disputes belong to food unsafe under self-perception, rather than unsafe in the real sense. Other possible causes cannot be excluded.

The results of this study reveal that the government's protective behavior toward occupational claimants has a positive effect on the number of occupational claim cases and the government's regulatory behavior toward occupational claimants has a positive effect on the rate of losing occupational claim cases. The former can be confirmed by the relationship between the government's introduction of the Consumer Protection Law and the Food Safety Law and the timing of the amendments and the number of occupational claim cases. The latter can be confirmed from the data in Table 1, which shows the relationship between the official series of regulatory behaviors and social media involvement and the rate of losing occupational claim cases.

\section{Conclusion}

It is proposed that laws and regulations should be in line with international standards, highlight the legal thinking and the concept of the rule of law, return to the original legislative intent, refer to the Shanghai model, multisectoral linkage, and build a five-in-one mechanism of "consumers, operators, media, government, and justice" to coordinate the management of occupational claims (see Figure 8) and to crack down on extortion and abuse of the right to file complaints in the process of occupational claims and contribute to the creation of a good business environment.

We call for the government to introduce business norms and policies on rewards and penalties to promote social and economic development, protect consumers' legitimate consumption channels and improve people's livelihood, actively protect the legitimate rights and interests of consumers, clarify the negative attributes of occupational claims, regulate the phenomenon, and provide policy guarantees for the improvement of the business environment. The media should report fairly and impartially on the quality of the operator's products and truthfully expose the malpractice of occupational claims to contribute to the creation of a positive business environment, improve public confidence, and enhance public integrity. The judiciary should keep up with the times and actively amend the adaptive provisions of punitive laws and regulations in an effort to win social support and maintain social stability. Other individuals in the society should actively improve their moral cultivation, resolutely resist the consumption of poor quality products, firmly support laws and regulations, refrain from participating in occupational claims, take the initiative to report the phenomenon of occupational claims, and make contributions to progress of social civilization.
We propose that the official should be designed from the top to build a system of integrity and rights protection, remove the "fighting against counterfeit" halo from the head of occupational claims, clarify the negative characterization of occupational claims, and crack down on bad behavior such as maliciously reporting and filing a complaint against businesses, disrupting the normal working of the state administration, abusing the right to file complaints and report lawsuits, and undermining the business environment. Public security depatments, market supervision departments, and other relevant departments should jointly establish a list of occupational claimants, linked to personal integrity, and people with such behavior will have their credit scores deducted, and some of their rights will be restricted to a certain extent (such as restricting loans, restricting highspeed rail and airplane travel, restricting the purchase of luxury goods, and treating them differently in various aspects such as complaint handling, administrative punishment, and administrative review), thus creating a sense of self-restraint [19]. The illegal and criminal acts of malicious occupational claimants should be severely punished. Typical cases of malicious occupational claimants of illegal and criminal punishment should be widely publicized as an example to others.

The government should address possible loopholes of common themes of occupational claims from the perspective of law management rules, such as the scope of business, food safety, advertising, unfair competition, and other areas, introduce relevant regulations as soon as possible to regulate the behavior of manufacturers and distributors, and clarify that if the illegal act is minor and corrected in time without causing harmful consequences, no administrative penalty shall be imposed. There is no opportunity for occupational claimants to take advantage of laws and regulations, compressing their space to profit through complaints and reports. At the same time, the rules for identifying occupational claimants combining their characteristics should be clarified and the situation where normal consumers are tempted to enter the occupational claim trap because of the interests should be avoided.

We will try to implement a five-in-one mechanism of "consumers, operators, media, government, and justice" to manage occupational claims by starting to control the two main bodies of occupational claims, respectively. It is firmly believed that occupational claims will eventually step off the stage of history. The withdrawal of occupational claims is the basic guarantee for the normal operation of social economy and business and is also the inevitable result of the construction of social credit system and the healthy development of social civilization.

\section{Data Availability}

The data used to support the findings of this study are included within the article.

\section{Conflicts of Interest}

The authors declare that they have no conflicts of Interest. 


\section{Acknowledgments}

This work was supported in part by the Natural Science Foundation of Anhui Province of China (1908085MG233), Quality Engineering for Research Projects of the Anhui Department of Education (nos. 2020jsk1341 and 2020wyxm108), and Projects for Policy Consultation of Health Development Strategy Research Center in Anhui Province (2021szk004).

\section{References}

[1] H. Yin, "Legal regulation of professional anti-counterfeiting in the field of food," Food Science, vol. 39, no. 9, pp. 341-346, 2018.

[2] C. Hall and F. Osses, "A review to inform understanding of the use of food safety messages on food labels," International Journal of Consumer Studies, vol. 37, no. 4, pp. 422-432, 2013.

[3] G. Dannemann, An Introduction to German Civil and Commercial Law, pp. 1-20, British Institute of International \& Comparative Law, London, UK, 1993.

[4] J. John and M. Christine, Punitive Damages, pp. 2-24, Singapore:Law \& Practice, Singapore, 2000.

[5] R. Liu, Z. Gao, H. A. Snell, and H. Ma, "Food safety concerns and consumer preferences for food safety attributes: evidence from China," Food Control, vol. 112, no. 6, 107157 pages, 2020.

[6] Y. An and Y. Uniersity, "Dimension of resolving administrative punishment disputes in the new 'Food Safety Law," Food \& Machinery, vol. 35, no. 4, pp. 68-71, 2019.

[7] Y. Cai, The Cause, Legeal Limit and Countermeasures of Buying Fake Products on Purpose, pp. 13-15, Xiamen University, Xiamen, China, 2017.

[8] J. Wang and J. Zhong, "Reestablishment of punitive compensation system for food safety," Social Science of Beijing, vol. 0, no. 6, pp. 13-30, 2012.

[9] J. Sun, L. Zhang, R. Sun et al., "Exploring the influence of resiliency on physician trust in patients: an empirical study of Chinese incidents," PLoS One, vol. 13, no. 12, pp. e0207394-15, 2018.

[10] J. J. Sun, Z. B. Zheng, X. L. Jiang et al., "Research on management of doctor-patient risk and status of the perceived behaviors of physician trust in the patient in China: new perspective of management of doctor-patient risk," Mathematical Problems in Engineering, vol. 2020, no. 2145029, pp. 1-8, 2020.

[11] J.-J. Sun, P. Ping-Wang, Y.-N. Du, and L Jun, "Analysising the influence factors of single task pricing based on public packet system: an Empirical Study in China," Journal of Physics: Conference Series, vol. 1437, no. 012100, pp. 1-6, 2020.

[12] J. Sun, R. Sun, Y. Jiang et al., "The relationship between psychological health and social support: evidence from physicians in China," PLoS One, vol. 15, no. 1, pp. e0228152-19, 2020.

[13] W. L. Fang, Q. Zhang, N. Z. Ma, J Zhang, Z. Q Ma, and J. J Sun, "Association between MCP-1 gene and SLE: a meta-analysis," Journal of the European Academy of Dermatology and Venereology : JEADV, vol. 34, no. 4, pp. e198-200, 2020.

[14] C. Zhang, R. Liu, L. Zhang, and L. Dong, "Investigation and research on food safety knowledge, attitude and behavior of university students in kunming based on big data analysis," Journal of Physics: Conference Series, vol. 1648, no. 022032, pp. 1-6, 2020.
[15] P. András and J. Krisch, "Food safety in the public awareness," Analecta Technica Szegedinensia, vol. 9, no. 1, pp. 25-30, 2015.

[16] M. Su and Y. Wang, "New countermeasures and thoughts on the issue of regulating occupational claims in Shanghai," Business Economic Review, vol. 21, no. 1, pp. 44-52, 2020.

[17] European Commission, Commission Recommendation on the Use of a Harmonized Methodology for Classifying and Reporting Consumer Complaints and Enquiries, 2010, http:// europy.cu/legislation_summaries/consumers/consumerinfor mation/co0014_cn.htm.

[18] A. Frumento and S. Korenman, "SEC whistleblower retaliation - and the federal securities laws - after Digital Realty," Journal of Investment Compliance, vol. 19, no. 3, pp. 22-32, 2018.

[19] M. T. Howard, "Food hygiene regulation and enforcement policy in the UK: the underlying philosophy and comparisons with occupational health and safety law," Food Service Technology, vol. 4, no. 2, pp. 69-73, 2004. 